\title{
Soluble oligomeric amyloid- $\beta$ induces calcium dyshomeostasis that precedes synapse loss in the living mouse brain
}

\author{
Michal Arbel-Ornath ${ }^{1 \dagger}$, Eloise Hudry ${ }^{1 \dagger}$, Josiah R. Boivin ${ }^{1}$, Tadafumi Hashimoto ${ }^{1,2}$, Shuko Takeda ${ }^{1}$, \\ Kishore V. Kuchibhotla ${ }^{1,3}$, Steven Hou ${ }^{1}$, Carli R. Lattarulo ${ }^{1}$, Arianna M. Belcher ${ }^{1}$, Naomi Shakerdge ${ }^{1}$, Pariss B. Trujillo ${ }^{1}$, \\ Alona Muzikansky ${ }^{4}$, Rebecca A. Betensky ${ }^{4}$, Bradley T. Hyman ${ }^{1}$ and Brian J. Bacskai ${ }^{*}$
}

\begin{abstract}
Background: Amyloid- $\beta$ oligomers (OAB) are thought to mediate neurotoxicity in Alzheimer's disease (AD), and previous studies in $A D$ transgenic mice suggest that calcium dysregulation may contribute to these pathological effects. Even though AD mouse models remain a valuable resource to investigate amyloid neurotoxicity, the concomitant presence of soluble $A \beta$ species, fibrillar $A \beta$, and fragments of amyloid precursor protein (APP) complicate the interpretation of the phenotypes.

Method: To explore the specific contribution of soluble oligomeric $A \beta(O A \beta)$ to calcium dyshomeostasis and synaptic morphological changes, we acutely exposed the healthy mouse brain, at 3 to 6 months of age, to naturally occurring soluble oligomers and investigated their effect on calcium levels using in vivo multiphoton imaging.

Results: We observed a dramatic increase in the levels of neuronal resting calcium, which was dependent upon extracellular calcium influx and activation of NMDA receptors. Ryanodine receptors, previously implicated in AD models, did not appear to be primarily involved using this experimental setting. We used the high resolution cortical volumes acquired in-vivo to measure the effect on synaptic densities and observed that, while spine density remained stable within the first hour of oA $\beta$ exposure, a significant decrease in the number of dendritic spines was observed $24 \mathrm{~h}$ post treatment, despite restoration of intraneuronal calcium levels at this time point.

Conclusions: These observations demonstrate a specific effect of OA $B$ on NMDA-mediated calcium influx, which triggers synaptic collapse in vivo. Moreover, this work leverages a method to quantitatively measure calcium concentration at the level of neuronal processes, cell bodies and single synaptic elements repeatedly and thus can be applicable to testing putative drugs and/or other intervention methodologies.
\end{abstract}

Keywords: Alzheimer's disease, Amyloid $\beta$ oligomers, Calcium, In vivo imaging

\section{Background}

Alzheimer's disease $(\mathrm{AD})$ is a devastating age-related neurological disorder characterized by the accumulation of extracellular amyloid $\beta(A \beta)$ peptides and intraneuronal neurofibrillary tangles. Fibrillar amyloid plaques constitute a major diagnostic hallmark of the disease and correlate with deleterious local effects including gliosis, neuritic

\footnotetext{
*Correspondence: bbacskai@partners.org

Dr. Arbel-Ornath and Dr. Hudry are co-first authors.

${ }^{\dagger}$ Equal contributors

${ }^{1}$ Alzheimer Research Unit, Department of Neurology, Massachusetts General Hospital and Harvard Medical School, 114, 16th St., Charlestown, MA 02129, USA Full list of author information is available at the end of the article
}

dystrophies and synapse loss $[1,2]$. However, accumulating data suggest that small soluble aggregates of $A \beta$ (oligomers, oA $\beta$ ) mainly contribute to neuronal toxicity [3-7], accumulating in the vicinity of senile plaques and at the synapse [8]. Despite these important findings, no direct evidence has specifically linked the presence of oligomers in their natural form with neuronal dysfunction and spine morphological changes in vivo. While synthetic $A \beta$ peptides have been extensively used in the past, they showed a relatively weak potency as compared with "native" oligomers from AD brains in physiological concentrations. In transgenic mice, the 
concomitant presence of full-length human APP and its downstream catalytic fragments has prevented us from specifically addressing oA $\beta$-related neurotoxicity. We therefore developed an assay to directly examine the consequences of naturally occurring oA $\beta$ on the intact mouse brain using longitudinal multiphoton calcium imaging, and observed acute changes in calcium homeostasis, followed by synaptic loss.

The calcium hypothesis of $\mathrm{AD}$ argues that $\mathrm{A} \beta$ peptides impact neuronal calcium homeostasis, leading to synaptic failure, spine loss, neural network disruption and cognitive deficits [9-11]. Indirect evidence suggests that calcium alterations may be an early neuropathological change associated with mild cognitive impairment in AD patients [12-14]. A $\beta$-induced stress has been experimentally linked with abnormal activation of calcium dependent molecular cascades [5, 15], alteration of long term potentiation [16] and memory deficits $[16,17]$. The development of new calcium sensors and their combination with in vivo twophoton imaging has further allowed a direct evaluation of calcium changes in $\mathrm{AD}$ mouse models, demonstrating in particular a dramatic increase in resting calcium levels in a subset of neurites surrounding amyloid deposits [18]. Increased proportions of hypoactive and hyperactive neurons have been reported in transgenic animals, the latter being found in clusters near amyloid plaques [19]. At the network level, a gradual decline in visual sensory performances has been observed in APP mice, a phenomenon correlated with the amyloid load [20-22]. Intriguingly, most of these studies did not detect changes before amyloid deposition, with only one previous work reporting hyperactivity associated with synthetically crosslinked dimers in vivo [6]. Taken together, testing the hypothesis that physiologically relevant oA $\beta$ causes local neuritic calcium elevation in the intact brain has not been achieved.

In the present study, we investigated the effect of naturally occurring soluble oA $\beta$ on neuronal calcium homeostasis in adult wild type animals. Acute application of oA $\beta$, prepared from conditioned media isolated from transgenic primary neurons $(\mathrm{TgCM})$, to the mouse brain surface dramatically increased neuronal resting calcium levels, whereas no change could be observed when conditioned media collected from the wild-type littermates cultures (WtCM) was used. This effect was abolished after immunodepletion of $A \beta$, thus specifically linking the presence of neurotoxic $\mathrm{oA} \beta$ with intraneuronal calcium dysregulation. Because MK-801 efficiently blocked oA $\beta$-induced $\mathrm{Ca}^{2+}$ increase, we also concluded that calcium dysregulation was primarily mediated through NMDA receptors, whereas antagonists of intracellular calcium channels were ineffective. In this regard, the current work addresses a longstanding controversy about whether oA $\beta$ activates the release of internal calcium stores or opens cell surface receptors. In addition, while the calcium rise was rapidly buffered, synapse loss was only detected after $24 \mathrm{~h}$, demonstrating that oA $\beta$-induced functional alterations precede morphological changes in vivo. Lastly, the approach used here to repeatedly measure calcium concentrations in vivo in the different neuronal compartments, including soma, dendrites and synaptic elements, may find broad applications to evaluate modulators of oA $\beta$ neurotoxicity and investigate the impact of various soluble neurotoxic species relevant in other neurodegenerative diseases.

\section{Methods}

\section{Animals}

Tg2576 males (Taconic Farms), which heterozygously overexpress human APPswe under the PrP promoter, were mated with wild-type females (B6;SJL) for preparation of primary cortical neurons. In vivo imaging experiments were performed using wild-type C57BL/6 males (3-6 months of age, Charles River). Each experimental group consisted of 3 to 6 animals.

\section{Preparation of wild type and transgenic neuronal conditioned media and $A \beta$ immunodepletion}

Cortical neurons were prepared as previously described [15] and plated on 35-mm culture dishes coated with poly-D-lysine (Sigma-Aldrich) and maintained in Neurobasal/B-27 media. Tissue from each embryo was collected and used for genotyping using PCR. Conditioned media was collected at 14 days in vitro (DIV) from either transgenic cultures $(\mathrm{TgCM})$ or their wild-type littermates (WtCM). The concentrations of $\mathrm{A} \beta 40$ and $\mathrm{A} \beta 42$ were quantified by a mouse/human ELISA kit (Wako).

Immunodepletion of human $\mathrm{A} \beta$ from $\mathrm{TgCM}$ was performed overnight using the mAb 6E10 (Covance) and protein G sepharose beads (Sigma-Aldrich). Briefly, to avoid non-specific binding, protein $\mathrm{G}$ beads were washed with cold Neurobasal medium and incubated with $1 \mathrm{ml}$ of $\mathrm{TgCM}$ for $30 \mathrm{~min}$ at $4{ }^{\circ} \mathrm{C}$ while shaking. The mixture was then centrifuged and the beads were discarded. The supernatant was further incubated with $100 \mu \mathrm{l}$ pre-washed protein $\mathrm{G}$ beads and $9 \mu \mathrm{g}$ of $6 \mathrm{E} 10$ antibody for $5 \mathrm{~h}$ at $4{ }^{\circ} \mathrm{C}$ while shaking. The supernatant was then collected and $A \beta$ content was measured using a human/mouse ELISA kit (Wako).

\section{Size exclusion chromatography of condition media}

Size exclusion chromatography (SEC) was performed as previously described [5]. Briefly, TgCM or WtCM was collected from 14 DIV neurons and centrifuged at 3,000 g at $4{ }^{\circ} \mathrm{C}$ in Amicon Ultra-15ML $3 \mathrm{~K}$ to concentrate proteins approximately fivefold. Concentrated $\mathrm{TgCM}$ or WtCM was separated by tandem Superdex 75 10/300 GL columns in $50 \mathrm{mM}$ ammonium acetate, $\mathrm{pH}$ 8.5, with AKTA purifier 10 and dialyzed against PBS. A $\beta 40$ content within 
the different fractions was measured after dialysis of the fractions with PBS using mouse/human ELISA kit (Wako). Fractions were also subjected to oligomer-specific ELISA kit (IBL). Assay was performed according to the manufacture instructions.

\section{Viral vector construction and production}

The YC3.6 cDNA was cloned into an AAV2 backbone, under a hybrid cytomegalovirus (CMV) immediate-early enhancer/chicken $\beta$-actin promoter/exon1/intron and before the woodchuck hepatitis virus posttranscriptional regulatory element (WPRE). High titers of AAV serotype 8 were produced using the triple transfection protocol by both the Harvard and UPENN Vector Cores. Viruses were tittered by quantitative PCR and the final concentrations of these AAV viral stocks reached $4 \times 10^{12} \mathrm{vg} / \mathrm{ml}$.

\section{Stereotactic intraparenchymal injection of AAV-CBA-YC3.6} Stereotactic intracortical injections of AAV-CBA-YC3.6 were performed as described previously [23]. Briefly, animals were anesthetized by intraperitoneal injection of ketamine/xylazine $(100 \mathrm{mg} / \mathrm{kg}$ and $50 \mathrm{mg} / \mathrm{kg}$ body weight, respectively) and positioned on a stereotactic frame (Kopf Instruments). Injections of vector were performed in the somatosensory cortex with $3 \mu \mathrm{l}$ of viral suspension using a 33-gauge sharp needle attached to a 10- $\mu$ l Hamilton syringe (Hamilton Medical), at a rate of $0.1 \mu \mathrm{l} / \mathrm{min}$. Stereotactic coordinates of the injection sites were calculated from bregma (anteroposterior $-1 \mathrm{~mm}$, mediolateral $\pm 1 \mathrm{~mm}$ and dorsoventral $-1 \mathrm{~mm}$ ).

\section{Cranial window implantation}

One month after injection of AAV-CBA-YC3.6, mice were anesthetized with isoflurane (1-1.5\%) and a cranial window was implanted by removing a piece of skull above the somatosensory cortex and replacing it with a $8 \mathrm{~mm}$ diameter cover glass (as described previously [24]). For all experiments, the dura mater was removed prior to window installation. Texas Red dextran (70 kDa; $12.5 \mathrm{mg} / \mathrm{ml}$ in PBS; Molecular Probes) was injected into a lateral tail vein before imaging to provide a fluorescent angiogram. Mice were imaged first to determine resting calcium at baseline. The window was then opened and closed again along with either WtCM, TgCM or depleted-TgCM diluted 1:1 with PBS (final volume applied was $50 \mu \mathrm{l}$ ). The window, containing the applied solution, was then resealed with dental cement. One hour later, each animal was reimaged at the same fields of view to determine the relative changes in $\left[\mathrm{Ca}^{2+}\right](\Delta \mathrm{R} / \mathrm{Ri})_{\mathrm{i}}$. To test the effect of different calcium channel inhibitors, both dantrolene $(5 \mu \mathrm{M})$ and MK-801 $(5 \mu \mathrm{M})$ were incubated on the brain for 10 min before topical application with TgCM and each inhibitor mixed together for another hour.

\section{In vitro resting calcium imaging and measurements}

To evaluate the effect of calcium channel antagonists in vitro using Tg2576 primary neurons, we used two different ratiometric calcium indicators, indo-1 AM (Life technologies) and YC3.6. For indo 1- experiments, 1012 DIV cultures were incubated with $5 \mu \mathrm{M}$ indo- 1 AM for 45 min before imaging. For YC3.6 experiments, cells were transfected at 7 DIV with a pAAV-CBA-YC3.6 plasmid, using Lipofectamine 2000 (Life technologies), and imaged 2-3 days later. In both cases, hAPPsw transgenic neurons were imaged before and after bath application of an antagonist to calcium channels, using an LSM510 confocal microscope (Zeiss) with an environmental chamber that maintains constant conditions of $37{ }^{\circ} \mathrm{C}$ and $5 \% \mathrm{CO}_{2}$. In the case of indo-1, a chameleon laser (Coherent, Inc) generated two photon excitation at $750 \mathrm{~nm}$ and emitted light was collected at 390-465 nm and 468-533 $\mathrm{nm}$ corresponding to the calcium bound and unbound dye, respectively. For YC3.6 experiments, single photon excitation was used at $458 \mathrm{~nm}$ using an argon laser, and emitted light was collected using the 435-485 BP and 505 LP filters for detection of CFP and YFP fluorescence, respectively. We tested the effect of the following agents on resting calcium levels in transgenic neurons: $\mathrm{NiCl}_{2}(100 \mu \mathrm{M})$, nifedipine $(5 \mu \mathrm{M})$, $\omega$-conotoxin $(1 \mu \mathrm{M}), \mathrm{MK}-801(5 \mu \mathrm{M}), 2-\mathrm{APB}(100 \mu \mathrm{M})$ and dantrolene $(10 \mu \mathrm{M})$. All pharmacological agents were purchased from Sigma-Aldrich and dissolved either in double distilled water (ddw) or DMSO according to the manufacturer instructions. For indo-1 AM experiments, 5-6 fields of view were imaged randomly before and 10-15 min after bath application of the inhibitor. During culture experiments with YC3.6, a limited number of neurons were transfected, allowing us to reimage the same cells before and after treatment and thus to calculate the relative change in YFP/CFP ratio for each cell $(\triangle \mathrm{R} / \mathrm{Ri})$. Each experiment was repeated over 3-4 independent trials.

\section{In vivo multiphoton imaging}

For in vivo calcium imaging, an Olympus FluoView FV1000MPE multiphoton laser-scanning system mounted on an Olympus BX61WI microscope and an Olympus $25 \times$ dipping objective $(\mathrm{NA}=1.05)$ were used. A DeepSee Mai Tai Ti:sapphire mode-locked laser (Mai Tai; Spectra-Physics) generated two-photon excitation at $860 \mathrm{~nm}$, and detectors containing three photomultiplier tubes (Hamamatsu, Ichinocho) collected emitted light in the range of 460-500, 520-560 and 575-630 nm. Mice were placed on the microscope stage and heated using a heating pad with feedback regulation from a rectal temperature probe (Harvard apparatus). Four to six cortical volumes (Z-series, $127 \mu \mathrm{m} \times 127 \mu \mathrm{m}, 2 \mu \mathrm{m}$ slices, depth of 200-300 $\mu \mathrm{m}$ ) were taken per mouse, before and after topical application of conditioned media, 
at a resolution of $512 \times 512$ pixels. Because of those imaging settings (small field of view and slow scan speed) we mostly did not record any type of neuronal oscillations (1.66 s per frame $>1 \mathrm{~Hz}$ ). CFP and YFP PMTs settings remained unchanged throughout the different imaging sessions. Laser power was adjusted as needed.

\section{Image processing and analysis Cell cultures}

Cells were imaged using a confocal Zeiss LSM510 system. Images were processed and analyzed using ImageJ software (https://imagej.nih.gov/ij/). For indo-1 experiments, single plane images of channels corresponding to calcium bound and unbound dye were obtained. For each channel, the background, corresponding to the mode of the image, was subtracted and a median filter with radius 2 was applied before dividing the emitted fluorescence intensity of the calcium bound channel by the unbound dye channel, thus creating a ratio-image. For YC3.6 experiments, single channels corresponding to CFP and YFP fluorescence were processed in the same way described for indo-1, creating a YFP/CFP ratio image. In both cases, cell bodies were manually selected using the free hand tool, before and after application of an antagonist. The selected regions of interest were then placed on the ratio image and measured. To convert the measured ratios, either for indo-1 or YC3.6, into calcium concentrations, calibration experiments were performed in $\mathrm{CHO}$ cells using each calcium indicator and solutions with either zero or $39 \mu \mathrm{M}$ calcium in the presence of ionomycin (20 $\mu \mathrm{M}$, Life Technologies). This allowed the determination of the Rmin and Rmax for each indicator (indo-1: $R \min =0.54, R \max =3.04, Y C 3.6: R \min =0.19, R \max =$ 1.618). Ratios were then converted to actual calcium concentration using the indo- $1 \mathrm{~K}_{\mathrm{D}}(250 \mathrm{nM})$ and the $\mathrm{K}_{\mathrm{D}}$ of YC3.6 (278nM) with standard ratiometric equations $[25,26]$ :

$$
[C a 2+] i=K d^{\prime}\left(\frac{R-R \min }{R \max -R}\right)^{1 / n} ; K d^{\prime}=K d\left(\frac{S f 2}{S b 2}\right)^{1 / n}
$$

$S f 2$ and $S b 2$ represent the intensities at calcium free and calcium bound of the denominator (i.e. YFP or Indo-1 at $400 \mathrm{~nm}$ ).

Pseudocolored images presented were created in Matlab based on each indicator ratio, which was then converted to calcium concentration using the empirical Rmin and Rmax and assigned to the jet colormap. We used the ratio values to supply the Hue and Saturation (color) and the reference image to supply the Value (intensity).

\section{In vivo}

Image stacks were processed in Image J as follows: the background of CFP and YFP channels, corresponding to the mode of the deepest slice of the z-stack, was subtracted, and a median filter (radius 2) was applied before dividing the emitted fluorescence intensity of YFP by CFP, thus creating a ratio image. Neurites, cell bodies and dendritic spines were identified and selected using the YFP images. The YFP/CFP ratio was then measured for each ROI using the ratio images. YFP/CFP ratios were converted to $\left[\mathrm{Ca}^{2+}\right]_{i}$ with standard ratiometric equations (see above) using the in situ $\mathrm{K}_{\mathrm{D}}$ and Hill coefficient of YC3.6 we have previously determined [18]. We established the dynamic range of the indicator in-vivo, using the same in vivo experimental settings as all our in vivo experiments. Rmin and Rmax were calculated using the lowest $2.5 \%$ of plaque-associated neuritic dystrophies (in AD transgenic mice) and the upper $2.5 \%$ of neurites in a dying mouse, respectively $(R \min =0.79, R \max =4.5)$.

\section{Dendritic Spine analysis}

2D projections of YFP-filled neurites were obtained in ImageJ. Dendrites of at least $20 \mu \mathrm{m}$ long with prominent dendritic spine protrusions, were considered for analysis. Spines were selected manually and the relative changes in spine density were calculated for each neurite as compared with the average spine density before treatment for each animal. The nature of the treatment was kept blinded until statistical analyses.

\section{Statistical analyses}

To assess whether $\Delta \mathrm{R} / \mathrm{Ri}$ values were different between the treatment groups in Neurite, Soma and Spines, a linear mixed effects model was fitted with treatment group as fixed effect and mouse as random effect. The same model was used for the analysis of Spine density.

To assess whether there was a difference between before vs. after CM application measurements in each group separately, a linear mixed effect model was fitted for each treatment group predicting the difference (after-before) with a fixed effect of an intercept only and a random effect of mouse.

YFP/CFP ratios were pooled and presented in histograms. Histograms for each group before treatment was fitted with a normal distribution curve using the Graph Pad curve fitting tool. Fisher exact test was used for comparison of calcium overload before and after treatment within each group. For the cell culture data, one way ANOVA with post hoc Dunn's multiple comparison test was used for comparison of $\Delta \mathrm{R} / \mathrm{Ri}$ for each group and its vehicle treatment group ( $\mathrm{ddw}$ or DMSO). 


\section{Results}

Acute exposure of naturally occurring oA $\beta$ to the healthy living brain disrupts intraneuronal calcium homeostasis and synaptic integrity in vivo

Previous works have established that resting calcium levels and neuronal function are affected in transgenic mice with plaques, whereas no change was observed before amyloid deposition in most studies [18-21]. We have previously observed that TgCM treatment of wild type cortical neurons in vitro induced AD-like morphological changes that include calcium dyshomeostasis, calcineurin activation [15], dendritic spine loss and neuritic simplification [5].

To appreciate the specific contribution of soluble oA $\beta$ species to calcium dysregulation, we designed an acute in vivo assay of $A \beta$ neurotoxicity by topically applying oA $\beta$-enriched medium on the cortical surface of wild-type C57BL/6 mice. Culture medium from primary cortical neurons derived from Tg2576 embryos was used as a source of soluble oA $\beta$ (termed TgCM), which mainly contains low molecular weight oligomers (dimers to tetramers) as evidence from size exclusion chromatography (SEC) followed by A 340 ELISA (Additional file 1: Figure $\mathrm{S} 1)[5,15,27]$. To validate the presence of oA $\beta$ in the TgCM, the different SEC fractions were also subjected to oligomeric A $\beta$ ELISA (IBL) that utilizes the same antibody for capture and detection. Additional file 1: Figure S1B shows the presence of oA $\beta$ (at much lower levels compared to total $A \beta 40$ signal) in both the high and low molecular weight fractions. Higher levels were detected between fractions 11 and 16, which corresponds to $13.7 \mathrm{kDa}$ and smaller, very low levels were detected at fractions $25-28$, which correspond to $6.5 \mathrm{kDa}$ and lower. However, the signal at these fractions was very close to the limit of the ELISA kit sensitivity. This data suggest that that most $A \beta$ oligomers within the TgCM are of low molecular weight.

Conditioned media from non-Tg neurons (termed WtCM) and $\mathrm{A} \beta$ immunodepleted $\mathrm{TgCM}$ were used as controls. Within different batches of TgCM, A 340 and A 342 concentration respectively reached $4-8 \mathrm{nM}$ and 130-260pM, which corresponds to the levels detected in human cerebral spinal fluid [28]. Additionally, the concentration of oA $\beta$ in the TgCM reached $400 \mathrm{pM}$ to $600 \mathrm{pM}$, representing $7.5-10 \%$ of the total amount of $A \beta_{40}$. The content of murine $A \beta 40$ in several batches of WtCM ranged from $200 \mathrm{pM}$ to $500 \mathrm{pM}$ while murine A $\beta 42$ could not be detected.

To quantify absolute calcium levels in the brain, mice were injected with an AAV8 encoding the ratiometric calcium indicator yellow-cameleon YC3.6 [29]. Four weeks later, a craniotomy was performed above the somatosensory cortex and CFP and YFP fluorescent signals were measured. After evaluating the baseline neuronal resting calcium, the cranial window was reopened and either TgCM or WtCM, diluted 1:1 in PBS (final concentration of $\mathrm{A} \beta 40$ of $2 \mathrm{nM}$ in TgCM and $180 \mathrm{pM}$ in WtCM), was directly applied to the brain surface. Using the labeled brain vasculature as a guide, we were able to reimage the same field of view and calculate the relative changes in intracellular calcium. We imaged the first $300 \mu \mathrm{m}$ of the cortical surface, which consist of neurites and cell bodies located in layers II/III (Figs. 1a and 2a).

Using the YC3.6 $\mathrm{K}_{\mathrm{D}}(278 \mathrm{nM})$ previously calculated in cultures [18] and the dynamic range of the indicator (Rmin and Rmax) obtained from the in-vivo data acquired using the same microscope under the same settings (see Methods), we converted YFP/CFP ratios into absolute calcium concentrations. Our measurements indicate that $\left[\mathrm{Ca}^{2+}\right] \mathrm{i}$ is tightly regulated in wild type mice and reaches $70 \pm 4 \mathrm{nM}$ on average. The values of $\left[\mathrm{Ca}^{2+}\right] \mathrm{i}$ in neurites in wild type brain generally follow a normal distribution (Fig. 1c, $\mathrm{r}^{2}=0.99$ ). As expected, only rare neurites would be classified as having calcium overload at baseline (threshold defined as $\left[\mathrm{Ca}^{2+}\right]$ i greater than two SD above the mean of all neurites in the first imaging session, 90nM). Topical application of TgCM to the healthy brain progressively increased the YFP/CFP ratios and thus $\left[\mathrm{Ca}^{2+}\right] \mathrm{i}$, which reached a peak after an hour before returning to baseline levels by $5 \mathrm{~h}$ (Additional file 2: Figure S2). One-hour exposure with TgCM induced a dramatic elevation of intraneuronal calcium, as evident in the pseudocolored images and the right shift of the calcium distribution curves towards higher YFP/CFP ratio values (Fig. 1b, c). TgCM incubation resulted in a greater number of calcium-overloaded neurites (threshold for calcium overload is represented by a black line; $n=295$ neurites in 5 mice, calcium overload: before $=3.09 \%$, after $=25.82 \%, \quad p<0.0001$ Fisher exact test). Conversely, when mice were incubated with WtCM, no significant change in calcium levels was observed ( $n=409$ neurites in 5 mice, calcium overload: before $=$ $3.8 \%$, after $=1.38 \%, p=0.643$ Fisher exact test). To demonstrate that TgCM-induced elevation of $\left[\mathrm{Ca}^{2+}\right]_{\mathrm{I}}$ was directly related to the presence of $\mathrm{A} \beta$ peptides in the medium, we immunodepleted human $A \beta$ from the TgCM and followed the same experimental settings. Immunodepletion of $\mathrm{A} \beta$ with $6 \mathrm{E} 10$ antibody effectively removed about $80 \%$ of $\mathrm{A} \beta$ present in $\mathrm{TgCM}$ (initial concentration of $\mathrm{A} \beta 40$ in $\mathrm{TgCM}$ : $4.1 \mathrm{nM}$, after immunodepletion: $0.8 \mathrm{nM})$. The effect of TgCM was abolished after immunodepletion and only a modest non-significant trend of calcium overload was detected ( $n=206$ neurites in 3 mice, calcium overload: before $=1.9 \%$, after $=5.8 \%, p=0.07$ Fisher exact test, comparison of before and after YFP/CFP ratios $p<0.2847$ ).

Comparing resting calcium before and after treatment within the same neuronal processes, we observed that 


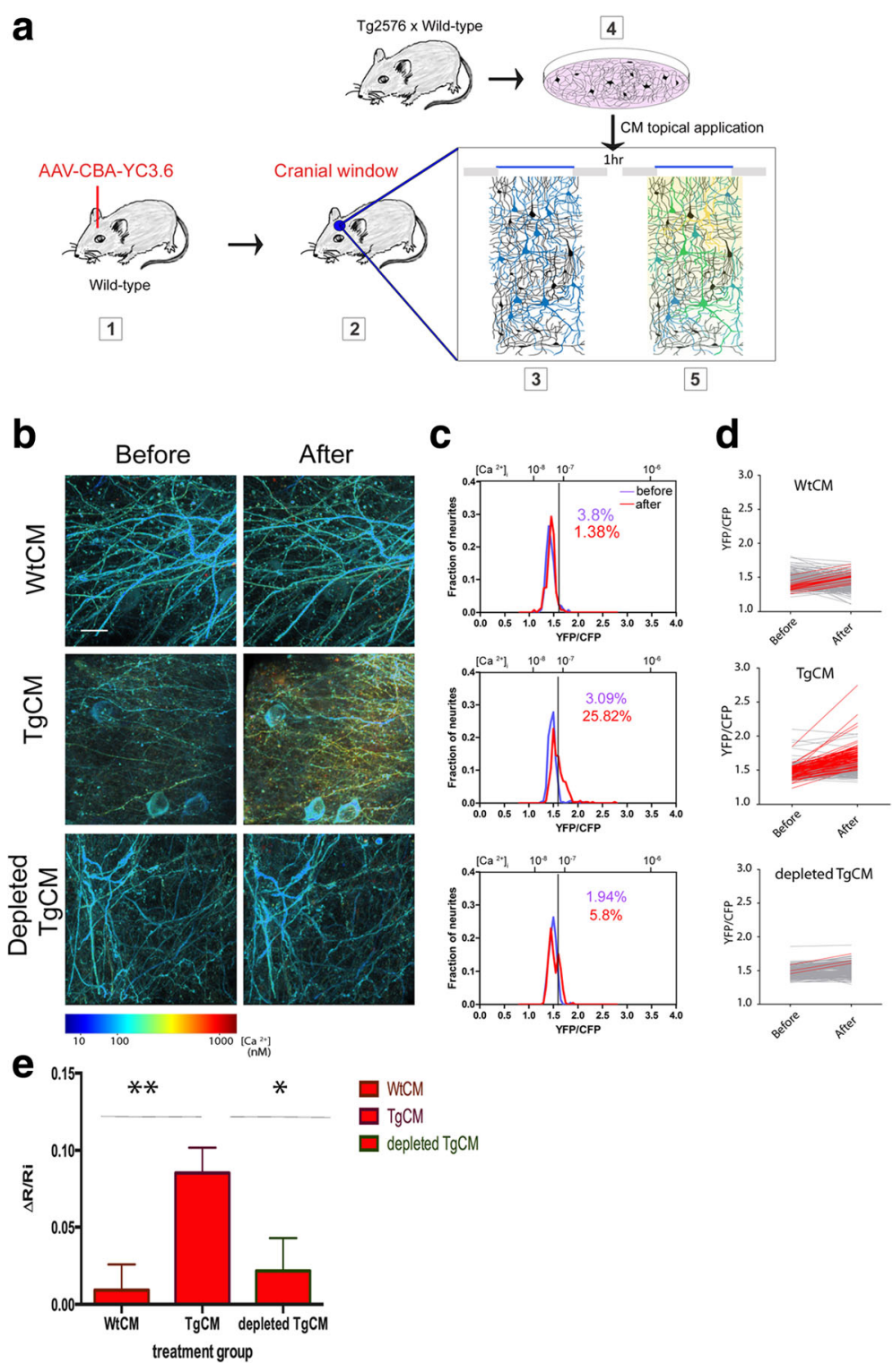

Fig. 1 Oligomeric $A \beta$ induces calcium overload in the healthy mouse brain. a A new experimental setting was designed to specifically address the effect of oA $\beta$ on calcium homeostasis in vivo. Wild-type C57BL/6 mice were injected with an AAV-CBA-YC3.6 and a cranial window was installed 4 weeks later. After a first imaging session at baseline, the window was opened and WtCM, TgCM or depleted TgCM was topically applied for 1 hour before reimaging again the exact same fields of view. b Neurites, consisting of dendrites and axons, filled with YC3.6 were imaged before and after treatment with TgCM, WtCM or depleted-TgCM. Images were pseudocolored according to calcium concentration (Scale bar $=20 \mu \mathrm{m})$. c Individual neurites were selected for measuring YFP and CFP ratio and calculating resting calcium levels. Distribution curves of $\left[\mathrm{Ca}^{2+}\right]_{i}$ (YFP/CFP ratio on the lower x-axis and $\left[\mathrm{Ca}^{2+}\right]_{\text {; }}$ on the upper $\mathrm{x}$-axis) are presented before (purple curve) and after treatment (red curve) for each experimental group. Acute exposure to $\mathrm{TgCM}$, but not to $\mathrm{WtCM}$ or immunodepleted-TgCM, resulted in a shift in the $\left[\mathrm{Ca}^{2+}\right]_{\text {; }}$ distribution towards higher ratio values, i.e. higher calcium concentrations. The black line indicates the threshold for calcium overload which represents 2 SD above the mean of ratios measured from all mice before treatment. The percentage of neurites with calcium overload before (purple) and after (red) treatment is noted on the graphs. Calcium overload was only significantly increased in the TgCM treated group from 3.09 to 25.82\% ( $p<0.0001$ Fisher exact test). $\mathbf{d}$ YFP/CFP ratios before and after treatment with WtCM, TgCM or depleted TgCM represented for each neurite. The red traces account for the neurites that showed an increase of $\geq 10 \%$ in YFP/CFP ratio after topical application of CM. $\mathbf{e}$ The relative change in ratio was calculated for each neurite and the mean + SEM of each group is presented (linear mixed effects model fitted with treatment group as fixed effect and mouse as random effect ${ }^{* *} p=0.0012,{ }^{*} p=0.0183$ ) 


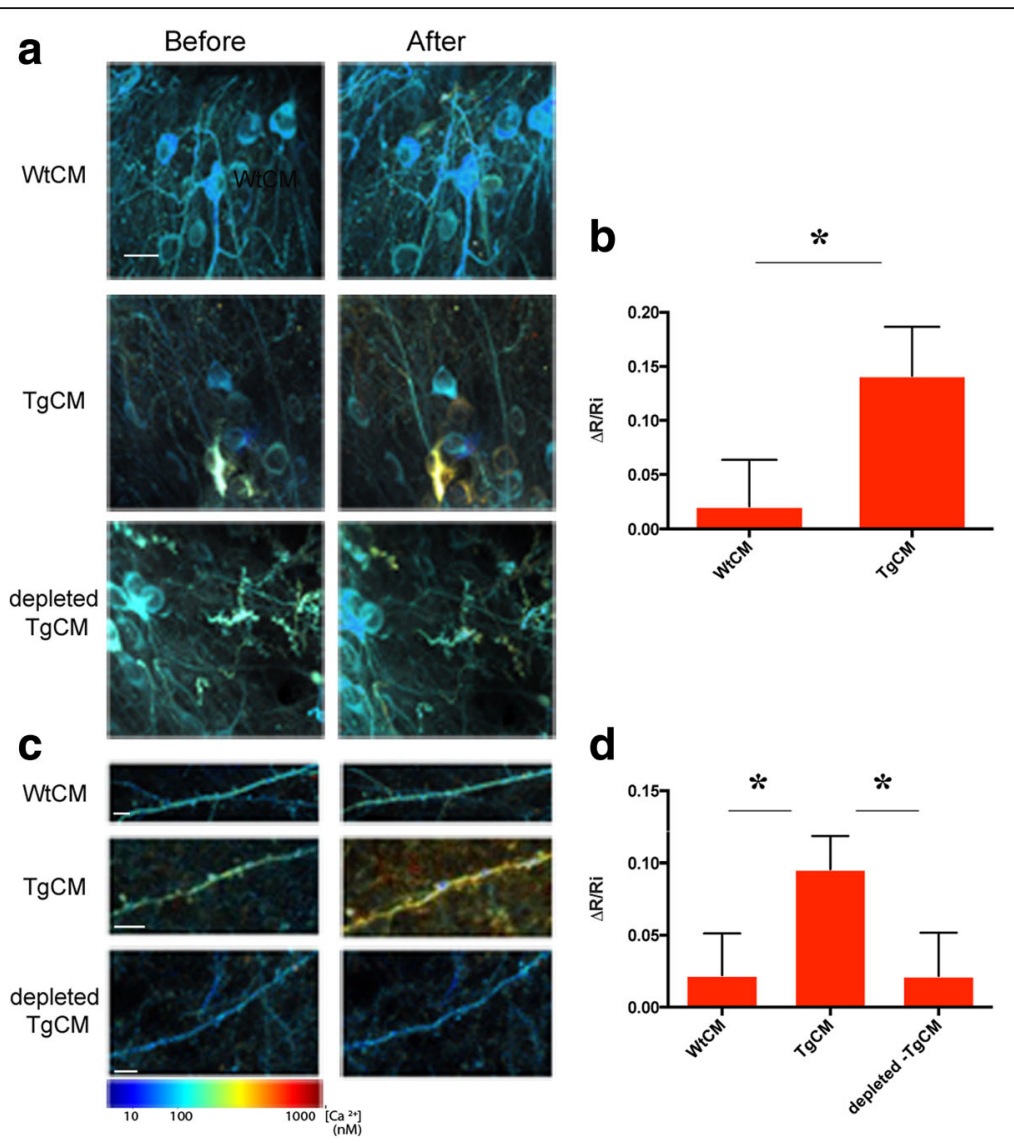

Fig. 2 Oligomeric A $\beta$ induces calcium overload in neuronal cell bodies and dendritic spines. Neuronal cell bodies (a,b) or dendritic spines (c,d) were imaged before and $1 \mathrm{~h}$ after treatment with conditioned media, and the YFP/CFP ratio and resting calcium were calculated for each compartment. Images were pseudocolored according to calcium concentrations. $\mathbf{b}$ In cell bodies, $\mathrm{TgCM}$, but not WtCM, induced an increase in resting calcium. (TgCM: $n=165$ cells, WtCM: $n=157$ cells, in 5 mice, pair-wise comparison of the relative change in $Y C$ ratio, $\left.{ }^{*} p=0.0458\right)$. $\mathbf{d}$ TgCM effect on $Y C$ ratio in dendritic spines followed the same trend as neurites and was significantly different from that of WtCM and depleted-TgCM (pair-wise analysis TgCM vs. WtCM * $p=0.0466$; TgCM vs. depleted-TgCM * $p=0.0494 ;$ WtCM vs. depleted-TgCM $p=0.9916$ ). Scale bars $=20 \mu m$ in (a) and $5 \mu \mathrm{m}$ in (c)

the YFP/CFP ratios were increased by $10 \%$ or more for the vast majority of $\mathrm{TgCM}$-treated neurites, whereas such a change was only occasionally observed after WtCM and depleted-TgCM incubation (Fig. 1d). From these values we calculated the relative change in YFP/ CFP ratio for each neurite $(\Delta \mathrm{R} / \mathrm{Ri}$, Fig. 1e) and showed that $\mathrm{TgCM}$ induced an average increase in the YFP/CFP ratio of $8.5 \pm 1.6 \%$ (from $70 \mathrm{nM}$ to about $85 \mathrm{nM}$ ). Application of $\mathrm{TgCM}$ was significantly different from that of $\mathrm{WtCM}$ and depleted-TgCM while the later two groups were not different from each other (Fig. 1e, linear mixed effect model. Overall change between the groups $p=$ 0.0029 , post hoc comparisons between every 2 groups: $p$ $=0.0012 \mathrm{TgCM}$ vs. WtCM; $p=0.0183 \mathrm{TgCM}$ vs. depleted TgCM; $p=0.6507 \mathrm{WtCM}$ vs. depleted-TgCM. $n=$ 295 neurites within 5 mice for $\mathrm{TgCM}, 405$ neurites within 5 mice for WtCM and 206 neurites picked from 3 mice for depleted-TgCM).
When only the overloaded neurites after TgCM treatment were analyzed, the average reached a mean change of $16.9 \pm 4.8 \%$ (from $70 \mathrm{nM}$ to $100 \mathrm{nM}$ ). Reimaging the same fields and analyzing the YFP/CFP ratios in the same neurites $5 \mathrm{~h}$ post treatment did not show any change from baseline (Additional file 2: Figure S2), suggesting that elevation in $\left[\mathrm{Ca}^{2+}\right]_{i}$ was a transient event rapidly buffered in the healthy brain of wild type mice.

When cell bodies were selected (Fig. 2a and b), resting calcium concentration at baseline was lower than the level measured in neurites, averaging at $58 \mathrm{nM}$. Exposure with oligomeric $\mathrm{A} \beta$ also disrupted calcium homeostasis in the neuronal soma as compared with WtCM treatment $(\Delta \mathrm{R} / \mathrm{Ri}: \mathrm{TgCM} 14.4 \pm 4.25 \%$, WtCM $2.09 \pm 4.2 \%$, pairwise comparison, $p=0.0458$ ). However, we could not analyze the depleted $-\mathrm{TgCM}$ as we could trace cell bodies only in one of 3 mice tested. TgCM treatment effect was significantly different from that of WtCM. 
Dendritic spines showed indistinguishable $\left[\mathrm{Ca}^{2+}\right] \mathrm{i}$ from that of the neurites (Fig. 2c, d; YFP/CFP ratios corresponding to about $72 \pm 10 \mathrm{nM}$ and $70 \pm 4 \mathrm{nM}$ in spines and neurites, respectively). Similarly to our observations in neurites, TgCM application led to a $9.6 \%$ $\pm 2.3 \%$ increase in calcium levels (comparison before and after TgCM: $p=0.0268)$. WtCM and depletedTgCM application did not have any effect (before vs. after comparison; WtCM: $p=0.3736$, depleted-TgCM: $p=0.5552$ ). The effect of TgCM on the relative change in calcium was significantly different from that of WtCM and depleted TgCM, which did not differ from each others (pair-wise comparisons; TgCM vs. WtCM $p=0.0466$, TgCM vs. depleted TgCM $p=0.0494$, WtCM vs. depleted $\operatorname{TgCM} p=0.9916)$. In contrast with the acute and dramatic impact of oA $\beta$ on intraneuronal calcium, no change in spine density was detected $1 \mathrm{~h}$ after treatment with TgCM (relative change compared with the average spine density before treatment: $-0.2 \% \pm$ $4.1 \%, p=0.9502,760$ spines counted in 4 mice) or with WtCM (relative change compared with the average spine density before treatment: $2.2 \% \pm 5.3 \%, p=0.708$ 578 spines counted within 3 mice, Fig. 3). However, a robust decrease in the density of dendritic spines was observed $24 \mathrm{~h}$ after TgCM application (relative change compared with the average spine density before treatment: $-28.7 \% \pm 4.3 \%, p<0.0001, n=635$ spines within 3 mice, Fig. 3), at a time when the calcium levels were restored to baseline (Additional file 2: Figure S2). By contrast, non-significant change in spine density was observed $24 \mathrm{~h}$ post application of WtCM (relative change compared with the average spine density before treatment $(8.9 \% \pm 4 \%, p=0.0555,1382$ spines counted within 3 mice, Fig. 3), suggesting that this observation did not derive from the surgical procedure itself. Pairwise analysis between the two groups (TgCM/WtCM) showed no difference at $1 \mathrm{~h}(p=0.7463)$ and significant change in spine density at $24 \mathrm{~h}(p<0.0001)$ after treatment.

\section{NMDA receptors mediate $\mathrm{A} A \beta$-induced increase in resting calcium}

Intracellular changes in neuronal $\left[\mathrm{Ca}^{2+}\right]_{\mathrm{i}}$ can result from increased entry of extracellular calcium, leakage of intracellular calcium stores or loss of buffering capacity. To determine the molecular mechanisms underlying TgCM-induced calcium dysregulation, we examined these possibilities in vitro and in vivo.

As a preliminary approach, we used cortical primary neurons cultured from Tg2576 embryos to perform an initial screen of various calcium channel inhibitors. These neurons chronically secrete human $A \beta$ that oligomerize to form predominantly species from dimers to tetramers after 14DIV (Additional file 1: Figure S1).

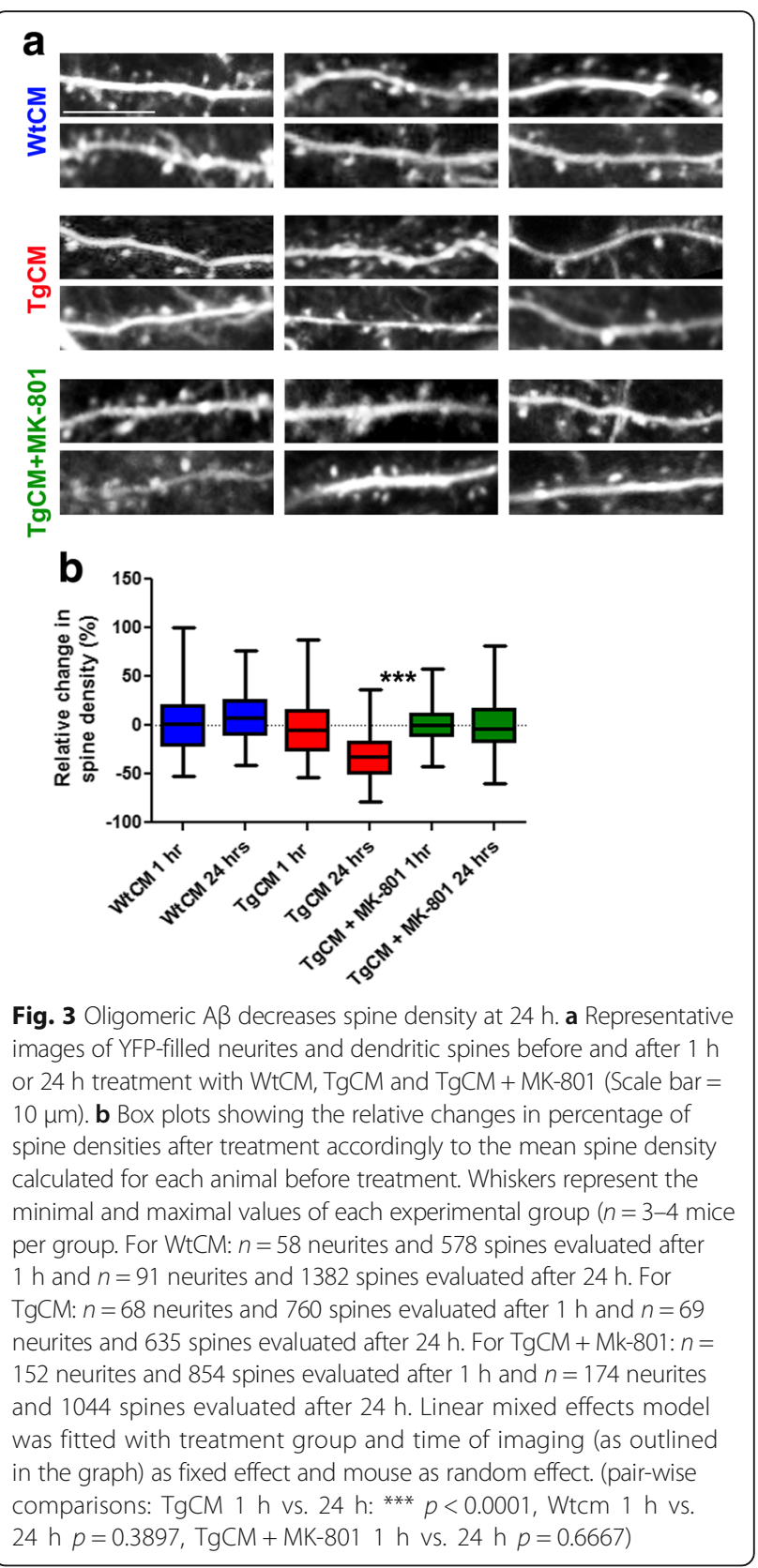

We have previously demonstrated that, similarly to wild type neurons treated with TgCM, Tg2576 neurons also exhibit spine loss and decreased neurite arborization $[5,15]$. We assessed the calcium levels with two different calcium probes: YC3.6 and the small molecule ratiometric indicator indo-1/AM. To explore the contribution of the extracellular calcium pool and the role of voltage gated calcium channels (VGCC), we incubated the cells with indo-1 AM and imaged before and $10 \mathrm{~min}$ after exposure to $0.5 \mathrm{mM} \mathrm{NiCl}_{2}$. Transgenic neurons in culture presented a wide distribution of calcium concentrations (Fig. 4a, note the right tail of the distribution curve). Before treatment, $21.3 \%$ of transgenic neurons showed 


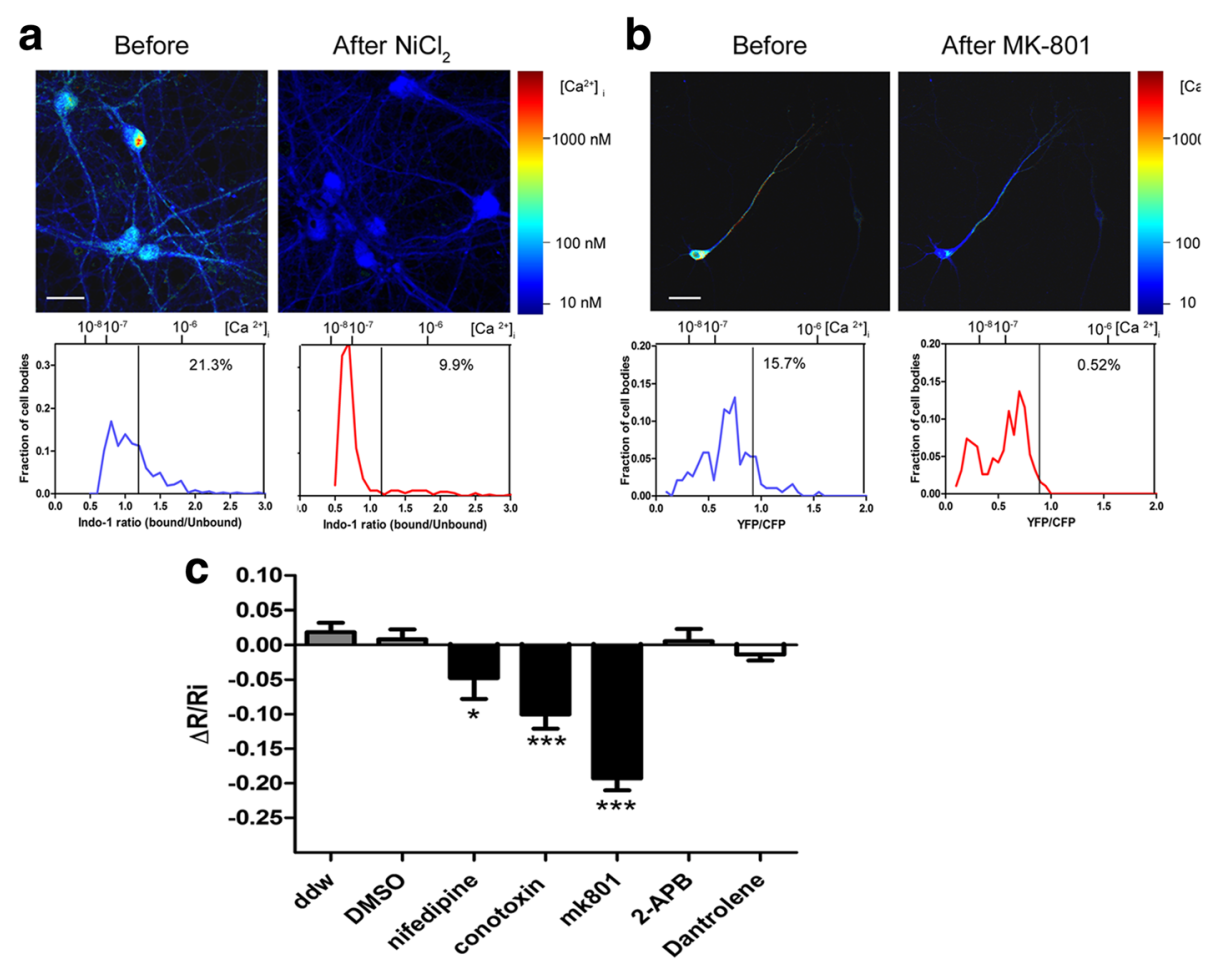

Fig. 4 Extracellular calcium is the source of calcium overload in primary neurons expressing human APP. a Tg2576 neurons were incubated with the ratiometric calcium indicator indo- $1 \mathrm{AM}$ and then imaged before and after application of $\mathrm{NiCl}_{2}$ to block all voltage gate calcium channels. The ratios of bound vs. unbound indo-1 were calculated, converted to calcium concentration and pseudocolored using the jet color map. Distribution curves of $\left[\mathrm{Ca}^{2+}\right]_{i}$ (bound/unbound ratio on the lower $x$-axis and $\left[\mathrm{Ca}^{2+}\right]_{i}$ on the upper $\mathrm{x}$-axis) are presented in the lower panel showing a wider distribution at baseline, which became more narrow and was shifted to the left after application of $\mathrm{NiCl}_{2}$. The black line indicates the threshold for calcium overload. The percentage of neurons with calcium overload, noted on the graphs before and after treatment, is significantly reduced by $\mathrm{NiCl}_{2}$ from 21.3 to $9.9 \%$ ( $n=366$ neurons before treatment and 321 after treatment in three separate experiments, Fisher exact test, $p<0.0001)$. b Neurons were transfected with YC3.6 and imaged before and after application of the NMDA receptor antagonist, MK-801. Ratios were converted to calcium levels and pseudocolored as in A. Upper panel shows resting calcium measured in the same neuron before and after inhibition of NMDA receptors. Distribution curves of $\left[\mathrm{Ca}^{2+}\right]_{i}$ (YFP/CFP on the lower $\mathrm{x}$-axis and $\left[\mathrm{Ca}^{2+}\right]_{\text {; }}$ on the upper $\mathrm{x}$-axis) are shown on the lower panel. Again, the wide distribution of calcium initially observed in transgenic neurons was shifted to the left after treatment with MK-801, dramatically reducing calcium overload from 15.7 to $0.5 \%$ ( $n=189$ neurons in 4 separate experiments, Fisher exact test $p<0.0001)$. c Summary bar graph for experiments with antagonists for different calcium channel measured with YC3.6 as described in B. The relative change in ratio ( $\Delta R / R i)$ after exposure with each inhibitor was calculated for individual cells and presented here as the group mean + SEM (each inhibitor was tested in three independent experiments: vehicles: $d d w-n=243$, DMSO $-n=161$; inhibitors: Nifedipine (L-type voltage channels) $-n=158$, $\omega$-conotoxin ( $N$-type channels) $-n=141$, 2-APB (IP $R$ R) - 173, dantrolene (RyR) 208). The effect of the treatment was tested by comparing each inhibitor to its appropriate vehicle using one way ANOVA with post hoc Dunn's Multiple comparison test $\left({ }^{*} p<0.05,{ }^{* *} p<0.01,{ }^{* * *} p<0.0001\right)$. (Scale bar $=50 \mu \mathrm{m}$ )

calcium overload (marked by a black line, $\mathrm{R}=1.32$, $467 \mathrm{nM}$ ), similar to our previous in vivo observations using this APP mouse model [18]. A 10-min incubation with $\mathrm{NiCl}_{2}$ significantly decreased the resting calcium levels and reduced the percentage of calcium overloaded cells from $21.3 \%$ to $9.9 \%$ (Tg before: $n=366$ neurons in 3 experiments. Tg after $\mathrm{NiCl}_{2}: n=321$ neurons in 3 experiments, $p<0.0001$, Fisher exact test). We then performed similar experiments with specific pharmacological blockers of several calcium channels (nifedipine for L-type VGCC, $\omega$-conotoxin for N-type VGCC and MK-801 for NMDA-R), as well as inhibitors of intracellular calcium release from the ER (2-APB for $\mathrm{IP}_{3}$ receptors and dantrolene for ryanodine receptors). These experiments were performed in transgenic neurons transfected with YC3.6 and the sparse expression of YC3.6 allowed us to re-visit each cell after application and thus appreciate the relative change in ratio for each neuron $(\Delta \mathrm{R} / \mathrm{Ri})$. As evident in Fig. 4c, vehicles alone (water or DMSO) did not affect the resting calcium in cells. We observed that N-type, L-type VGCC and NMDA receptor antagonist were effective in reducing $\left[\mathrm{Ca}^{2+}\right]_{i}$ in the presence of oA $\beta$ by $4.7 \%, 10.05 \%$ and $19.31 \%$, respectively (One way ANOVA with post hoc Dunn's multiple comparison test for comparison across all groups: Nifedipine vs. DMSO: $p<0.05$, $\omega$-conotoxin vs. ddw: $p<0.0001$, MK-801 vs. ddw: $p<0.0001)$. MK-801 led to the most dramatic effect (Fig. $4 b, c$ ), shifting the distribution curve to the left and reducing calcium overload from 15.7 to $0.52 \%$ ( $p<0.0001$ Fisher exact test). Dantrolene and $2-\mathrm{APB}$, ryanodine and $\mathrm{IP}_{3}$ receptors antagonists 
that block calcium release from the ER, did not alter the resting calcium levels of $\mathrm{Tg}$ primary neurons. The moderate decrease in $\left[\mathrm{Ca}^{2+}\right]_{i}$ observed when nifedipine or $\omega$-conotoxin along with the more dramatic effect of MK-801 strongly support a major role for extracellular calcium as the source for calcium overload.

To test if oA $\beta$-induced calcium dysregulation also relies on extracellular stores and NMDAR activation in vivo, MK-801 $(5 \mu \mathrm{M})$ was applied on the surface of the brain for $10 \mathrm{~min}$ before and along with the application of TgCM. As shown in Fig. 5, TgCM failed to affect resting calcium in mice pretreated with MK-801 $(\Delta \mathrm{R} / \mathrm{Ri}$ comparing before and after MK- $801+\mathrm{TgCM}$ treatment: $p=0.7719)$. The percentage of calcium overloaded neurites also remained unchanged after MK-801/TgCM application (1.67 to $3.5 \%, n=656$ neurites from 7 mice, $p=0.0548$ Fisher exact test), while $\mathrm{TgCM}$ alone resulted in $25.8 \%$ of neurites showing calcium overload $(p<0.0001$, Fisher exact test). Additionally, we did not see any significant spine loss $1 \mathrm{~h}$ or $24 \mathrm{~h}$ after topical application of MK$801 / \mathrm{TgCM}$ (relative change compared with the average spine density before treatment: at $1 \mathrm{~h}: 0.4 \% \pm 3.3 \%, p=$ 0.9123 , and at $24 \mathrm{~h}: 2.4 \% \pm 3.3 ; n=4$ mice), implying that the presence of MK- 801 also counteracted the deleterious impact of oligomeric $A \beta$ species on synapse loss previously observed with $\mathrm{TgCM}$ alone at $24 \mathrm{~h}$. Importantly, MK-801 alone did not significantly changed calcium overload $(2.79 \%$ to $2.4 \%$ overload before and after, $p=0.37$, fisher exact test, $n=322$ neurites in 3 mice Fig. 5e), thus demonstrating that the impact of this inhibitor was directly associated with oA $\beta$-dependent activation of NMDAR in the first place. In contrast, treatment with dantrolene $(5 \mu \mathrm{M})$ did not counteract the effect of $\mathrm{TgCM}$ $(\Delta \mathrm{R} / \mathrm{Ri}$ comparing before and after dntrolene $+\mathrm{TgCM}$ treatment: $p=0.0003$ ).As evident by the change in the shape of the neurite distribution curve and the increased percentage of calcium overloaded neurites (from 2.07 to $21.23 \% ; n=674$ neurites from 4 mice, $p<0.0001$ Fisher
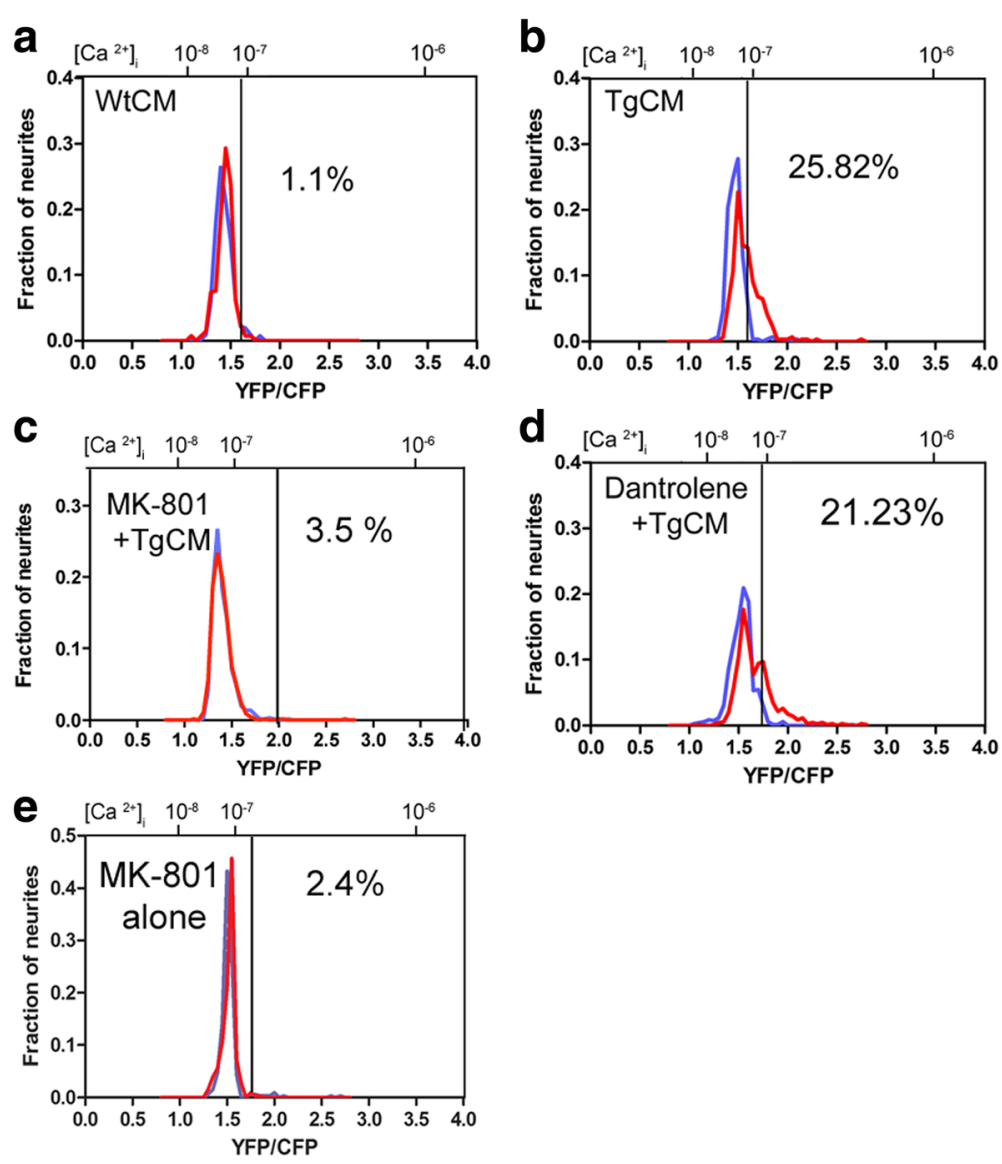

Fig. 5 Oligomeric A $\beta$ induces calcium overload through activation of NMDA receptors in vivo. The antagonists MK-801 and Dantrolene were applied 10-min before and during TgCM application. Distribution curves of $\left[\mathrm{Ca}^{2+}\right]_{i}$ (YFP/CFP ratio on the lower $\mathrm{x}$-axis and $\left[\mathrm{Ca}^{2+}\right]_{i}$ on the upper $x$-axis) are presented before (purple curve) and after treatment (red curve) for mice treated with WtCM (a) TgCM (b) MK- $801+\operatorname{TgCM}(\mathbf{c})$, dantrolene + $\operatorname{TgCM}(\mathbf{d})$ and MK-801 alone (e). The black line indicates the threshold for calcium overload. The percent of overloaded neurites is noted on each graph. Treatment with MK-801, but not of dantrolene, abolished the effect of TgCM on resting calcium (pair-wise comparisons of the relative change in YC ratio: TgCM vs. TgCM + MK-801 $p=0.0221$; TgCM vs. TgCM + Dantrolene $p=0.7656 ;$ TgCM + MK-801 vs. TgCM + Dantrolene $p=0.0077$ ) 
exact). To conclude, MK-801 and dantrolene led to an opposite effect on resting calcium once applied to the brain along with $\mathrm{TgCM}$ (pair-wise comparison $\mathrm{TgCM}+$ MK-801 vs. TgCM + dantrolene: $p=0.0077)$, suggesting that extracellular soluble amyloid species initially act through activation of these calcium channels in vivo, while the calcium retained in the ER does not seem to play a primary role.

\section{Discussion}

Disruption of intracellular calcium balance has been invoked as a potential mechanism of physiological and pathophysiological changes associated with normal aging [30] and, to a greater extent, with a variety of neurologic disorders including schizophrenia [31], bipolar disorder [32], autism spectrum disorder [33], Parkinson's disease [34, 35], Huntington disease [36] and AD [10, 11, 37-39]. The relationship between the pathological hallmarks of $\mathrm{AD}$ and abnormal calcium homeostasis has been a focus of investigation, and while neurofibrillary tangles seemed to affect neither resting $\left[\mathrm{Ca}^{2+}\right]_{\mathrm{i}}[40]$ nor neuronal responses to stimuli [41], the amyloid pathology has been linked to increased resting calcium [18], neuronal hyperactivity [19] and a gradual decline in neuronal performance in response to visual stimuli $[20,21]$.

Accumulating evidence suggests that soluble oA $\beta$ are more potent neurotoxic species than $\mathrm{A} \beta$ fibrils, leading to synaptic and neural network dysfunction [3, 4, 42-44]. Though the effect of different species of oA $\beta$ has been tested in culture models, studying their relevance in vivo has been challenging because of the concomitant presence of amyloid plaques $[8,45]$. In this study, we specifically investigated the effect of naturally secreted soluble species of $A \beta$, primarily oA $\beta$, on calcium homeostasis in the healthy living brain. We utilized conditioned media collected from APP transgenic cortical neurons as the source of oligomeric $A \beta$. Unlike synthetic $A \beta$, which generates oligomers and fibrils within minutes to hours, naturally secreted $A \beta$ peptides mainly assemble into low molecular weight species from dimers to tetramers. We demonstrated that, when oA $\beta$ was acutely applied to the cortical surface of the healthy mouse brain after cranial window implantation, the resting calcium levels were dramatically increased in all cellular compartments including neuronal soma, processes and dendritic spines. While it is conceivable that the surgical procedure itself sensitizes neurons towards $A \beta$ neurotoxicity, the calcium rise could not be attributed solely to the experimental approach itself. Indeed, removal of $\mathrm{A} \beta$ from the conditioned media or, alternatively, acute application of conditioned media from wild type neurons, abolished this effect. A $\beta$-induced elevation of resting calcium was significant $1 \mathrm{~h}$ after application but could no longer be detected in the same brains after $5 \mathrm{~h}$, suggesting clearance of the peptide assemblies, and/or recovery via intracellular buffering mechanisms. Interestingly, the relatively fast increase of intraneuronal calcium levels after exposure to $A \beta$ leads to long-lasting morphological alterations with a significantly decreased spine density detected only $24 \mathrm{~h}$ after treatment with $\mathrm{TgCM}$ while no change could be detected at $1 \mathrm{~h}$. The extent of oA $\beta$-induced spine loss is similar to what has been reported in the immediate vicinity of amyloid plaques, where high concentrations of $\mathrm{oA} \beta$ are thought to exist $[8$, 45]. The difference in kinetics between oA $\beta$-dependent calcium overload and synaptic collapse strongly argues in favor of a primary neuronal dysfunction that precedes morphological changes at the synapse, perhaps via activation of calcineurin or other calcium dependent signaling pathways $[5,15,27]$. This is of particular interest considering that spine loss is the parameter that correlates best with cognitive impairment in AD patients [46, 47].

Understanding the source of the calcium entry in the presence of $\mathrm{oA} \beta$ and the channels involved is important as calcium influx through different channels may trigger various signaling cascades which independently impact gene transcription and neuronal homeostasis [48]. The role of extracellular calcium and its influx through the activation of NMDA receptors was demonstrated in vivo, as oA $\beta$-dependent calcium rise was prevented by incubation with MK-801. Indeed, $A \beta$ has been shown to reduce long term potentiation (LTP) and facilitate long term depression (LTD), processes that involved trafficking of glutamate receptors $[49,50]$. In addition, prefibrillar amyloid and $A \beta$ oligomers have been shown to directly interact with glutamatergic receptors, activate NMDAR and result in calcium increase in primary neurons [51-53]. While those in vitro studies have established a direct association between oA $\beta$ and NMDAR, our results do not exclude the possibility that intermediate steps also participate in the rise of intraneuronal calcium levels. For example, pathologically elevated levels of $A \beta$ have been shown to block glutamate uptake at the synaptic cleft, leading to increased glutamate levels, which could also activate synaptic NMDA receptors [54]. Whether or not the activation of NMDAR is a direct or indirect effect of extracellular oA $\beta$, our data strongly suggest that the rise in intracellular calcium via NMDAR may impair synaptic plasticity and spine density, and thus represent the initial steps in the pathological changes that occur in AD.

ER calcium stores have been suggested to play a role in regulation of $A \beta$ production $[55,56]$ and calcium release from the ER via ryanodine and $\mathrm{IP}_{3}$ receptors has also been implicated in calcium dyshomeostasis in $\operatorname{AD}[11,57,58]$. Specifically, chronic treatment with the ryanodine receptor antagonist, dantrolene, was shown to normalize ER calcium responses, improve cognitive deficits and modulate the amyloid pathology in mouse models of AD [59]. Conversely, our data suggest that oA $\beta$ initially facilitates 
calcium entry from extracellular pools, at least largely via NMDA receptors, whereas ryanodine receptors do not appear to play a role primarily. It is possible that the ER pools are involved in a second step in calcium-dependent calcium release from the ER, resulting in further rise in cytosolic calcium levels. In the brains of $\mathrm{AD}$ mouse models chronically exposed to $A \beta$ oligomers and fibrils, the sustained increase in resting calcium [18] may result from a concomitant dysregulation of extracellular calcium entry or intracellular calcium buffering systems that further induce downstream events such as synapse loss and alterations in APP processing. This may not be the case in the healthy brain in which calcium is highly regulated, explaining why the effect of oA $\beta$ on $\left[\mathrm{Ca}^{2+}\right]_{i}$ is not abolished by blocking RyR, as the initial rise in calcium is not dependent on ER stores.

Finally, we cannot exclude that exposure of the cortical surface to oA $\beta$ impacts intraneuronal calcium homeostasis via non-cell autonomous mechanisms, eventually involving the participation of astroglial cells as well [60]. The effect of oA $\beta$ on cultured astrocytes has indeed been investigated over the past $[61,62]$, showing in particular that oligomerized $A \beta$ can induce astrocytic glutamate release in an $\alpha 7 \mathrm{nAChR}$-dependent manner, activate extrasynaptic NMDAR and lead to synaptic loss. In vivo studies in AD mice have revealed that calcium transients in astrocytes were more frequent and synchronously coordinated in transgenic animals as compared with controls [63, 64], an effect potentially mediated by paracrine purinergic signaling that could be blocked by P2Y receptors inhibitors [65]. However, most of the work conducted in animals has been done using transgenic mouse models, so the sole effect of $\mathrm{oA} \beta$ on astrocytic calcium homeostasis remains to be elucidated. Additionally, studying the respective impact of oligomeric amyloid species concomitantly on neurons and astrocytes will give further information about the initial molecular mechanisms in play.

In light of these observations, it is clear that therapeutic strategies aimed at reducing or inhibiting calcium influx into cells through NMDAR may be of importance. In parallel, efforts to prevent or reduce the levels of soluble oA $\beta$ levels will likely lead to treatments that effectively delay or restore neuronal dysfunction in AD.

\section{Conclusions}

The present study demonstrates that low-molecular weight species of Amyloid $\beta$ can acutely disrupt neuronal calcium homeostasis in non-transgenic animals through the activation of NMDA receptors. Interestingly, although calcium levels are rapidly restored to baseline, decreased spine density is detected $24 \mathrm{~h}$ after exposure to oA $\beta$, suggesting that calcium dyshomeostasis precedes synaptic morphological changes. This work implicates small oA $\beta$ species in the deleterious effects that occur during degenerative processes at the synapse.

\section{Additional files}

\begin{abstract}
Additional file 1: Figure S1. Biochemical characterization of $A \beta$ oligomers present in $\mathrm{Tg}$ conditioned media (TgCM). a Representative profile showing the amount of A 340 detected by ELISA in each fraction after separation of the different oligomeric species present in $\mathrm{TgCM}$ (red bars) by size-exclusion chromatography (SEC, Superdex 75 SEC columns). The molecular weight markers $(\mathrm{kDa})$ that ran at the same conditions are indicated above (arrowheads). b Measurements of oligomeric A $\beta$ within each SEC fraction show that most of $O A \beta$ is of low molecular weight (fractions 12-18).. A smaller peak of high-molecular weight species was also detected in TgCM (fractions 2-6 in both ELISAs). (TIF 1492 kb)
\end{abstract}

Additional file 2: Figure S2. Time course of $O A \beta$-induced increase in resting calcium levels after acute exposure with $\mathrm{TgCM}$ on a healthy brain. C57BL/6 mice were injected with AAV-CBA-YC3.6 into the somatosensory cortex and acutely exposed to TgCM containing oAB. The changes in YFP/CFP ratios in the neurites were measured at baseline before treatment and $30 \mathrm{~min}, 1 \mathrm{~h}$ and $5 \mathrm{~h}$ after topical application of TgCM. A progressive increase in the levels of resting calcium (YFP/CFP ratio and the actual calcium levels on the lower and upper $x$-axis, respectively) was detected that reached a peak after $1 \mathrm{~h}$ (20.6\% of overloaded neurites), before returning to baseline levels after $5 \mathrm{~h}$ ( $1.7 \%$ overloaded neurites). (TIF $37844 \mathrm{~kb}$ )

\section{Acknowledgements}

Not applicable.

\section{Funding}

This work was funded by NIH EB000768, S10 RR025645, Alzheimer Association IIRG-11-205935, NIH-MARC U*STAR 5T34GMO92711-04 and NIA R01 AG044263.

\section{Availability of data and materials}

The datasets used and/or analysed during the current study available from the corresponding author on reasonable request.

\section{Authors' contributions}

$\mathrm{MAO}$ and $\mathrm{EH}$ designed the experiments, collected and analyzed data and wrote the manuscript. JRB performed the in vitro experiments in primary neurons and analyzed data. TH and ST performed the SEC analysis of WtCM and TgCM. KVK and SH wrote the ImageJ and Matlab macros in order to calculate the YC ratios and generate the illustrative pseudocolored images. CRL, AMB, NS and PBT helped with the image analyses. AM and RAB performed the statistical analyses. $\mathrm{BTH}$ and BJB oversaw the experimental design, discussed the data and edited the manuscript. All authors read and approved the final manuscript.

\section{Authors' information}

Not applicable.

\section{Competing interests}

The authors declare that they have no competing interests.

\section{Consent for publication \\ Not applicable.}

\section{Ethics approval}

All studies were performed with the approval of the Massachusetts General Hospital Animal Care and Use Committee and in compliance with the National Institute of Health guidelines for the use of experimental animals.

\section{Publisher's Note}

Springer Nature remains neutral with regard to jurisdictional claims in published maps and institutional affiliations. 


\section{Author details}

'Alzheimer Research Unit, Department of Neurology, Massachusetts General Hospital and Harvard Medical School, 114, 16th St., Charlestown, MA 02129, USA. ${ }^{2}$ Department of Neuropathology, The University of Tokyo, Tokyo, Japan. ${ }^{3}$ Skirball Institute, NYU School of Medicine, New York, NY 10016, USA. ${ }^{4}$ Department of Biostatistics, Harvard School of Public Health, 50 Staniford Street, Boston, MA, USA.

\section{Received: 13 September 2016 Accepted: 17 March 2017}

\section{Published online: 21 March 2017}

\section{References}

1. Spires TL, Meyer-Luehmann M, Stern EA, McLean PJ, Skoch J, Nguyen PT, Bacskai BJ, Hyman BT. Dendritic spine abnormalities in amyloid precursor protein transgenic mice demonstrated by gene transfer and intravital multiphoton microscopy. J Neurosci. 2005;25:7278-87.

2. Knowles RB, Wyart C, Buldyrev SV, Cruz L, Urbanc B, Hasselmo ME, Stanley $H E$, Hyman BT. Plaque-induced neurite abnormalities: implications for disruption of neural networks in Alzheimer's disease. Proc Natl Acad Sci U S A. 1999:96:5274-9.

3. Selkoe DJ. Soluble oligomers of the amyloid beta-protein impair synaptic plasticity and behavior. Behav Brain Res. 2008;192:106-13.

4. Shankar GM, Li S, Mehta TH, Garcia-Munoz A, Shepardson NE, Smith I, Brett FM, Farrell MA, Rowan MJ, Lemere CA, et al. Amyloid-beta protein dimers isolated directly from Alzheimer's brains impair synaptic plasticity and memory. Nat Med. 2008;14:837-42.

5. Wu HY, Hudry E, Hashimoto T, Kuchibhotla K, Rozkalne A, Fan Z, SpiresJones T, Xie H, Arbel-Ornath M, Grosskreutz CL, et al. Amyloid beta induces the morphological neurodegenerative triad of spine loss, dendritic simplification, and neuritic dystrophies through calcineurin activation. J Neurosci. 2010;30:2636-49.

6. Busche MA, Chen X, Henning HA, Reichwald J, Staufenbiel M, Sakmann B, Konnerth A. Critical role of soluble amyloid-beta for early hippocampal hyperactivity in a mouse model of Alzheimer's disease. Proc Natl Acad Sci U S A. 2012;109:8740-5.

7. Viola KL, Velasco PT, Klein WL. Why Alzheimer's is a disease of memory: the attack on synapses by A beta oligomers (ADDLs). J Nutr Health Aging. 2008:12:51S-7S.

8. Koffie RM, Meyer-Luehmann M, Hashimoto T, Adams KW, Mielke ML, GarciaAlloza M, Micheva KD, Smith SJ, Kim ML, Lee VM, et al. Oligomeric amyloid beta associates with postsynaptic densities and correlates with excitatory synapse loss near senile plaques. Proc Natl Acad Sci U S A. 2009;106:4012-7.

9. Disterhoft JF, Moyer Jr JR, Thompson LT. The calcium rationale in aging and Alzheimer's disease. Evidence from an animal model of normal aging. Ann N Y Acad Sci. 1994;747:382-406.

10. Khachaturian ZS. Calcium hypothesis of Alzheimer's disease and brain aging. Ann N Y Acad Sci. 1994;747:1-11.

11. Chakroborty S, Stutzmann GE. Calcium channelopathies and Alzheimer's disease: Insight into therapeutic success and failures. Eur J Pharmacol. 2013.

12. Mattson MP. Calcium and neurodegeneration. Aging Cell. 2007;6:337-50.

13. Smith IF, Green KN, LaFerla FM. Calcium dysregulation in Alzheimer's disease: recent advances gained from genetically modified animals. Cell Calcium. 2005;38:427-37.

14. Reese LC, Laezza F, Woltjer R, Taglialatela G. Dysregulated phosphorylation of $\mathrm{Ca}(2+) / \mathrm{calmodulin}$-dependent protein kinase II-alpha in the hippocampus of subjects with mild cognitive impairment and Alzheimer's disease. J Neurochem. 2011;119:791-804.

15. Hudry E, Wu HY, Arbel-Ornath M, Hashimoto T, Matsouaka R, Fan Z, SpiresJones TL, Betensky RA, Bacskai BJ, Hyman BT. Inhibition of the NFAT pathway alleviates amyloid beta neurotoxicity in a mouse model of Alzheimer's disease. J Neurosci. 2012;32:3176-92.

16. Malleret G, Haditsch U, Genoux D, Jones MW, Bliss TV, Vanhoose AM, Weitlauf C, Kandel ER, Winder DG, Mansuy IM. Inducible and reversible enhancement of learning, memory, and long-term potentiation by genetic inhibition of calcineurin. Cell. 2001;104:675-86.

17. Kayyali US, Zhang W, Yee AG, Seidman JG, Potter H. Cytoskeletal changes in the brains of mice lacking calcineurin $A$ alpha. J Neurochem. 1997;68:1668-78.

18. Kuchibhotla KV, Goldman ST, Lattarulo CR, Wu HY, Hyman BT, Bacskai BJ. Abeta plaques lead to aberrant regulation of calcium homeostasis in vivo resulting in structural and functional disruption of neuronal networks. Neuron. 2008;59:214-25.
19. Busche MA, Eichhoff G, Adelsberger H, Abramowski D, Wiederhold KH, Haass C, Staufenbiel M, Konnerth A, Garaschuk O. Clusters of hyperactive neurons near amyloid plaques in a mouse model of Alzheimer's disease. Science. 2008:321:1686-9.

20. Grienberger $\mathrm{C}$, Rochefort NL, Adelsberger H, Henning HA, Hill DN, Reichwald J, Staufenbiel M, Konnerth A. Staged decline of neuronal function in vivo in an animal model of Alzheimer's disease. Nat Commun. 2012;3:774.

21. Rudinskiy N, Hawkes JM, Betensky RA, Eguchi M, Yamaguchi S, Spires-Jones TL, Hyman BT. Orchestrated experience-driven Arc responses are disrupted in a mouse model of Alzheimer's disease. Nat Neurosci. 2012;15:1422-9.

22. Stern EA, Bacskai BJ, Hickey GA, Attenello FJ, Lombardo JA, Hyman BT. Cortical synaptic integration in vivo is disrupted by amyloid-beta plaques. J Neurosci. 2004:24:4535-40.

23. Santacruz K, Lewis J, Spires T, Paulson J, Kotilinek L, Ingelsson M, Guimaraes A, DeTure M, Ramsden M, McGowan E, et al. Tau suppression in a neurodegenerative mouse model improves memory function. Science. 2005:309:476-81.

24. Skoch J, Hickey GA, Kajdasz ST, Hyman BT, Bacskai BJ. In vivo imaging of amyloid-beta deposits in mouse brain with multiphoton microscopy. Methods Mol Biol. 2005;299:349-63.

25. Grynkiewicz G, Poenie M, Tsien RY. A new generation of $\mathrm{Ca} 2+$ indicators with greatly improved fluorescence properties. J Biol Chem. 1985;260:3440-50.

26. Palmer AE, Tsien RY. Measuring calcium signaling using genetically targetable fluorescent indicators. Nat Protoc. 2006;1:1057-65.

27. Wu HY, Hudry E, Hashimoto T, Uemura K, Fan ZY, Berezovska O, Grosskreutz CL, Bacskai BJ, Hyman BT. Distinct dendritic spine and nuclear phases of calcineurin activation after exposure to amyloid-beta revealed by a novel fluorescence resonance energy transfer assay. J Neurosci. 2012;32:5298-309.

28. Mehta PD, Pirttila T, Mehta SP, Sersen EA, Aisen PS, Wisniewski HM. Plasma and cerebrospinal fluid levels of amyloid beta proteins 1-40 and 1-42 in Alzheimer disease. Arch Neurol. 2000;57:100-5.

29. Nagai T, Yamada S, Tominaga T, Ichikawa M, Miyawaki A. Expanded dynamic range of fluorescent indicators for $\mathrm{Ca}(2+)$ by circularly permuted yellow fluorescent proteins. Proc Natl Acad Sci U S A. 2004;101:10554-9.

30. Mattson MP, Magnus T. Ageing and neuronal vulnerability. Nat Rev Neurosci. 2006; 7:278-94.

31. Tesli M, Skatun KC, Ousdal OT, Brown AA, Thoresen C, Agartz I, Melle I, Djurovic S, Jensen J, Andreassen OA. CACNA1C risk variant and amygdala activity in bipolar disorder, schizophrenia and healthy controls. PLOS ONE. 2013;8, e56970

32. Green EK, Grozeva D, Jones I, Jones L, Kirov G, Caesar S, Gordon-Smith K, Fraser C, Forty L, Russell E, et al. The bipolar disorder risk allele at CACNA1C also confers risk of recurrent major depression and of schizophrenia. Mol Psychiatry. 2010;15:1016-22.

33. Lu AT, Dai X, Martinez-Agosto JA, Cantor RM. Support for calcium channel gene defects in autism spectrum disorders. Mol Autism. 2012;3:18.

34. Schapira AH. Calcium dysregulation in Parkinson's disease. Brain. 2013;136:2015-6.

35. Ilijic E, Guzman JN, Surmeier DJ. The L-type channel antagonist isradipine is neuroprotective in a mouse model of Parkinson's disease. Neurobiol Dis. 2011;43:364-71.

36. Bezprozvanny I. Role of inositol 1,4,5-trisphosphate receptors in pathogenesis of Huntington's disease and spinocerebellar ataxias. Neurochem Res. 2011;36:1186-97.

37. Bezprozvanny I, Mattson MP. Neuronal calcium mishandling and the pathogenesis of Alzheimer's disease. Trends Neurosci. 2008;31:454-63.

38. Bojarski L, Herms J, Kuznicki J. Calcium dysregulation in Alzheimer's disease. Neurochem Int. 2008:52:621-33.

39. Green KN. Calcium in the initiation, progression and as an effector of Alzheimer's disease pathology. J Cell Mol Med. 2009;13:2787-99.

40. Kopeikina KJ, Wegmann S, Pitstick R, Carlson GA, Bacskai BJ, Betensky RA, Hyman BT, Spires-Jones TL. Tau causes synapse loss without disrupting calcium homeostasis in the rTg4510 model of tauopathy. PLOS ONE. 2013;8, e80834.

41. Kuchibhotla KV, Wegmann S, Kopeikina KJ, Hawkes J, Rudinskiy N, Andermann ML, Spires-Jones TL, Bacskai BJ, Hyman BT. Neurofibrillary tangle-bearing neurons are functionally integrated in cortical circuits in vivo. Proc Natl Acad Sci U S A. 2014;111:510-4.

42. Shankar GM, Bloodgood BL, Townsend M, Walsh DM, Selkoe DJ, Sabatini BL. Natural oligomers of the Alzheimer amyloid-beta protein induce reversible synapse loss by modulating an NMDA-type glutamate receptor-dependent signaling pathway. J Neurosci. 2007;27:2866-75. 
43. Walsh DM, Selkoe DJ. A beta oligomers - a decade of discovery. J Neurochem. 2007;101:1172-84.

44. Cheng $I_{H}$, Scearce-Levie K, Legleiter J, Palop JJ, Gerstein H, Bien-Ly N, Puolivali J, Lesne S, Ashe KH, Muchowski PJ, Mucke L. Accelerating amyloidbeta fibrillization reduces oligomer levels and functional deficits in Alzheimer disease mouse models. J Biol Chem. 2007:282:23818-28.

45. Howlett DR, Bowler K, Soden PE, Riddell D, Davis JB, Richardson JC, Burbidge SA, Gonzalez MI, Irving EA, Lawman A, et al. Abeta deposition and related pathology in an APP $\times$ PS1 transgenic mouse model of Alzheimer's disease. Histol Histopathol. 2008;23:67-76.

46. Terry RD, Masliah E, Salmon DP, Butters N, DeTeresa R, Hill R, Hansen LA, Katzman R. Physical basis of cognitive alterations in Alzheimer's disease: synapse loss is the major correlate of cognitive impairment. Ann Neurol. 1991;30:572-80

47. DeKosky ST, Scheff SW, Styren SD. Structural correlates of cognition in dementia: quantification and assessment of synapse change. Neurodegeneration : a journal for neurodegenerative disorders, neuroprotection, and neuroregeneration. 1996;5:417-21.

48. West $A E$, Griffith $E C$, Greenberg ME. Regulation of transcription factors by neuronal activity. Nat Rev Neurosci. 2002;3:921-31.

49. Selkoe DJ. Alzheimer's disease is a synaptic failure. Science. 2002;298:789-91.

50. Kim JH, Anwyl R, Suh YH, Djamgoz MB, Rowan MJ. Use-dependent effects of amyloidogenic fragments of (beta)-amyloid precursor protein on synaptic plasticity in rat hippocampus in vivo. J Neurosci. 2001;21:1327-33.

51. Texido L, Martin-Satue M, Alberdi E, Solsona C, Matute C. Amyloid beta peptide oligomers directly activate NMDA receptors. Cell Calcium. 2011:49:184-90.

52. Pellistri F, Bucciantini M, Relini A, Nosi D, Gliozzi A, Robello M, Stefani M. Nonspecific interaction of prefibrillar amyloid aggregates with glutamatergic receptors results in $\mathrm{Ca} 2+$ increase in primary neuronal cells. J Biol Chem. 2008:283:29950-60.

53. Snyder EM, Nong Y, Almeida CG, Paul S, Moran T, Choi EY, Nairn AC, Salter MW, Lombroso PJ, Gouras GK, Greengard P. Regulation of NMDA receptor trafficking by amyloid-beta. Nat Neurosci. 2005;8:1051-8.

54. Li S, Hong S, Shepardson NE, Walsh DM, Shankar GM, Selkoe D. Soluble oligomers of amyloid Beta protein facilitate hippocampal long-term depression by disrupting neuronal glutamate uptake. Neuron. 2009;62:788-801.

55. Green KN, Demuro A, Akbari Y, Hitt BD, Smith IF, Parker I, LaFerla FM. SERCA pump activity is physiologically regulated by presenilin and regulates amyloid beta production. J Cell Biol. 2008;181:1107-16.

56. Cheung KH, Shineman D, Muller M, Cardenas C, Mei L, Yang J, Tomita T, Iwatsubo T, Lee VM, Foskett JK. Mechanism of Ca2+ disruption in Alzheimer's disease by presenilin regulation of InsP3 receptor channel gating. Neuron. 2008:58:871-83.

57. Christensen RA, Shtifman A, Allen PD, Lopez JR, Querfurth HW. Calcium dyshomeostasis in beta-amyloid and tau-bearing skeletal myotubes. J Biol Chem. 2004;279:53524-32.

58. Demuro A, Parker I. Cytotoxicity of intracellular abeta42 amyloid oligomers involves $\mathrm{Ca} 2+$ release from the endoplasmic reticulum by stimulated production of inositol trisphosphate. J Neurosci. 2013;33:3824-33.

59. Peng J, Liang G, Inan S, Wu Z, Joseph DJ, Meng Q, Peng Y, Eckenhoff MF, Wei H. Dantrolene ameliorates cognitive decline and neuropathology in Alzheimer triple transgenic mice. Neurosci Lett. 2012:516:274-9.

60. Osborn LM, Kamphuis W, Wadman WJ, Hol EM. Astrogliosis: An integral player in the pathogenesis of Alzheimer's disease. Prog Neurobiol. 2016;144:121-41.

61. Drews A, Flint J, Shivji N, Jonsson P, Wirthensohn D, De Genst E, Vincke C, Muyldermans S, Dobson C, Klenerman D. Individual aggregates of amyloid beta induce temporary calcium influx through the cell membrane of neuronal cells. Sci Rep. 2016;6:31910.

62. Talantova M, Sanz-Blasco S, Zhang X, Xia P, Akhtar MW, Okamoto S, Dziewczapolski G, Nakamura T, Cao G, Pratt AE, et al. Abeta induces astrocytic glutamate release, extrasynaptic NMDA receptor activation, and synaptic loss. Proc Natl Acad Sci U S A. 2013;110:E2518-27.

63. Kuchibhotla KV, Lattarulo CR, Hyman BT, Bacskai BJ. Synchronous hyperactivity and intercellular calcium waves in astrocytes in Alzheimer mice. Science. 2009;323:1211-5.
64. Takano T, Han X, Deane R, Zlokovic B, Nedergaard M. Two-photon imaging of astrocytic $\mathrm{Ca} 2+$ signaling and the microvasculature in experimental mice models of Alzheimer's disease. Ann N Y Acad Sci. 2007;1097:40-50.

65. Delekate A, Fuchtemeier M, Schumacher T, Ulbrich C, Foddis M, Petzold GC. Metabotropic $\mathrm{P} 2 \mathrm{Y} 1$ receptor signalling mediates astrocytic hyperactivity in vivo in an Alzheimer's disease mouse model. Nat Commun. 2014:5:5422.

\section{Submit your next manuscript to BioMed Central and we will help you at every step:}

- We accept pre-submission inquiries

- Our selector tool helps you to find the most relevant journal

- We provide round the clock customer support

- Convenient online submission

- Thorough peer review

- Inclusion in PubMed and all major indexing services

- Maximum visibility for your research

Submit your manuscript at www.biomedcentral.com/submit
) Biomed Central 